\title{
Distributed creative activity: expanding Tikhomirov's original notion of creative activity
}

\author{
Anthony Faiola \\ Indiana University-School of Informatics and Computing, Indianapolis, USA
}

\begin{abstract}
Tikhomirov's primary works are considered groundbreaking in the activity theory community. In particular, his efforts in understanding the positive effects of computers on the development of creative activity provide valuable instruction to activity theorists, especially with respect to their influence on new goal formation. Tikhomirov's quests to better understand "how computers affect the development of intellectual activity" are explicitly revealed in the clinical environment. As the intensive care unit is a preeminent environment to observe creative activity in real time, the primary problems of clinical team communication and collaboration, both aspects being related to joint activity, are identified. As one way to approach such a problem, Tikhomirov's theory on creative activity is explained in the context of information technology. Then, distributed cognition theory and creative activity theory are joined together and extended into distributedcreative activity theory, as an augmentation of complex interpersonal cognition through the use of health information technology.
\end{abstract}

Keywords: creative activity, critical care, distributed cognition, health information technology

\section{Introduction}

Oleg K. Tikhomirov remains one of the most significant contemporary Russian psychologists, whose name is among the other pioneers from the post-Vygotskian School, following the work of Aleksey Leontiev and Alexander Luria (Aleksandrova-Howell, Abramson, \& Craig, 2011; Babaeva et al., 2009). Tikhomirov's work relies on the cultural and historical aspects of activity in his study of creative activity theory, which expands the traditional subject matter in the study on the "psychology of creativity." Tikhomirov was the first to ask questions about the place of creative processes in everyday life, such as those in professional activity (Tikhomirov, 1971; Tikhomirov 1984). Tikhomirov's theory of creative activity argues that interaction is realized through the activity of social intercourse or collective activity (Rozin, 2002). He significantly altered the concept of "intuition" to include the observation of the mechanisms of unconscious processes in creative work, thus identifying the most essential moments of the creative act in addition to defin- 
ing intellectual activity as the central activity using knowledge. Thus, the study of creativity in the works of Tikhomirov and his students disclosed the interaction mechanisms between creative activities and the routine components in complex forms of intellectual activities for both the individual and society.

Tikhomirov (1999) notes that creative activity is not only characterized by motives, goals, and operations, but more significantly by "acts generating new motives, goals, and operations... the generation of new psychic formations, the real function of which is giving humans the opportunity to generate a new world of objects" (p. 350). Moreover, he says that goal formation (the generation of new goals in the subject's activity) is "one of the central acts in the structure of creative activity" (Tikhomirov, 1999, p. 351).

\section{Application of creative activity to information technology}

Secondary to his research on creativity, was Tikhomirov's work in the application of activity theory to information technology (IT). His groundbreaking contribution in the area of activity theory and computing identified IT as a new form of mediation. As Kozhanova (2003) notes, the traditional interpretation of activity did not account for diversity in the application of psychological aspects of humancomputer interaction (HCI), for either IT users or programmers. As such, much of Tikhomirov's most relevant work on creative activity is in the area of goal formation in the context of computing. Tikhomirov repeatedly posed two questions that are important for our discussion: "How does the computer affect the development of... intellectual activity?" and "What is the specific nature of human activity in human-computer systems as opposed to other forms of activity?" (Tikhomirov, 1972, 1988, 1999).

More importantly, in the chapter of his book entitled, "The theory of activity changed by information technology," Tikhomirov outlines his theory of creativity activity, but in the context of the new pervasiveness of computerization (Tikhomirov, 1999). He holds that creative activity is an "independent activity type," one that is often not discussed (Tikhomirov, 1999, p. 348). He argues that with the increasing appearance of new problems caused by IT, it is imperative that we consider these problems in the context of creativity; otherwise the "sphere of applicability of activity theory in psychology" will hinder our means to finding solutions (Tikhomirov, 1999, p. 349). The computer, he argues, is "not only a universal data-processing device, it is also a universal means of influencing human activity and, consequently, the human psyche" (Tikhomirov, 1999, p. 353).

In Tikhomirov's earlier research, he did not support the view that computerization could supplement or become a substitute for psychological processes (Tikhomirov, 1972). He argued that the computer should be viewed simply as a new sign system that mediates human activity with some forms of qualitative thinking, and that its primary function is to support efficient decision-making from the viewpoint of productivity. His original premise on the boundaries of computerized mediation did not take into account the evolutionary and ubiquitous nature of today's computing, and its influence on creative activity. Later, making reference to current empirical research, we see a slight shift in his view, where he addressed "goal formation as a manifestation of creativity in the dialogue with computers," 
showing its potential for "broadening human creative activity" (Tikhomirov, 1988; Tikhomirov, 1999, p. 353).

Particular to these studies is significant evidence of goal formation in the context of joint activity, including the complexity of social roles in an array of everyday events and environments. In such places and times, both routine and creative components of activity are manifested. Tikhomirov addresses the problem by making a distinction between creative and routine activities. In sum, creative activity is able to provide solutions to existing problems and those that are possible, those that move outside the routine, because creative activity is in a sense contrary to an algorithm, an "anti-algorithm" (Tikhomirov, 1999, p. 357). However, the "transfer of routine components to the computer means its inclusion in the performance of a social role" - this, Tikhomirov argues, results in the "fundamental transformation of the content of the social roles" (1999, p. 354).

We should also understand his latter expanded view as an enhancement of intelligence during joint activity, that is, subject-to-subject interpersonal cognition. ${ }^{*}$ Tikhomirov argues that in creative activity, the object appears in two forms: "as a new product of activity (a product that didn't exist before) and as an image of a yet to be created object" (Tikhomirov, 1999, p. 350). He clearly differentiates between creative and routine activities, with the former providing solutions to existing and possible problems (those outside routine). In sum, he states that goal-formation in the subject's activity is "one of the central acts in the structure of creative activity" (Tikhomirov, 1999, p. 351).

\section{Clinical activity: communication and collaboration}

Cognitive activity in healthcare is now a focal point of much research in the field of HCI. At the center of the discussion is the design and use of health information technology (HIT) as the key form of mediation in patient care during the diagnostic processes. The activity goal is the sustainability of patient health and the mitigation of human error. ${ }^{* *}$ Complex clinical spaces such as the intensive care unit (ICU) are especially susceptible to diagnostic error, not only because of the severity of the ailment and the fragility and instability of the patient, but also because clinical

* Tikhomirov defines interpersonal cognition as "forming concepts about another person's way of thinking." This includes the style, influence, and an understanding of their: 1) "goals and motives" and the problem to be solved, and 2) "capacity to look at an object-related situation and determine the true meaning of another's activity, especially in conflict situations..." (Tikhomirov, 1988, pp. 154-155).

** Optimizing intensive-care workflow while maximizing safety and quality of care remains at the forefront of the medical industry in the US, Europe, and Russia. In the intensive care unit (ICU), critically ill patients require frequent intervention and continuous and coordinated monitoring. Clinical workflow in the ICU is identified as the most complex environment in healthcare. With more than six million ICU admissions annually in the US, ICUs have both the highest annual mortality rate (12-17\%) and the highest costs in healthcare, accounting for $4.1 \%$ of the $\$ 2.6$ trillion in annual healthcare spending, or nearly $\$ 107$ million. Moreover, one quarter of all patients die in the ICU, of which $8 \%$ die due to misdiagnosis. More startling are the findings that ICU patients are the most monitored, tested, and examined of all hospital patients, yet the critical signs of a potentially deadly medical condition are sometimes missed. 
knowledge and patient data is distributed among clinical specialists and artifacts.* Specific studies demonstrate that $80 \%$ of medical error is attributed to human factors, e.g., clinician cognitive overload, task and workflow management, inadequate team collaboration, and communication breakdown (Winters et al., 2012).

As Tikhomirov (1988) points out, communication is a highly complex activity. Understanding the cognition of others relating to their goals and motives entails problems to solve and conflicts to resolve, especially in a joint activity. In particular, he includes: " 1 ) interpretation of another person's reactions and movements; 2 ) understanding (interpreting, explaining, forecasting) the results of object-related actions (directly observed or previously registered) of another person and of activity as a whole, of an individual act (he gives me things, consequently he likes me); and 3) understanding verbal output (oral and written) (p. 179). In fact, health interpersonal cognition could include the "forming of concepts about another person's way of thinking" (p. 179), including their style of thinking, and what others may think about my thinking. Often in team communication, interpersonal cognition involves an opposition of persons, and their goals and motives, resulting in communication breakdown and group conflict.

From the perspective of joint activity, neither the patient nor the clinical team can be observed in isolation, nor can their activities be observed as individual and secluded actions without influence from the environment, available HIT, or other stakeholders (Leont'ev, 1981). For this reason, the "concept of activity in psychology is a systemic concept, for activity is considered as a system. ... Through activity, humans interact with the surrounding world. Communication is an integral aspect of joint activity" (Tikhomirov, 1999, p. 348). As such, researchers will need to increasingly observe the connection between communication, effective collaborative work, reduction of error, and overall patient safety (Reader, Flin, Cuthbertson, 2007).

Team Communication: One of the most extensive human factors that investigations of error due to poor communication in the ICU discovered was that although nurse and doctor communication only occurred in $2 \%$ of all activities, these were associated with over a third of detected errors (Donchin et al., 1995). Research suggests that team communication failure between physicians and nurse intensivists ${ }^{* *}$ contributes to $91 \%$ of medical mishaps (Khairat \& Gong, 2011). Clinical communication among ICU team members is reported as the main cause of $75 \%$ of medical errors and $65 \%$ of sentinel events (Khairat \& Gong, 2011). Another study found 2,075 incidents of error that were related to communication breakdown in 23 ICUs

* For the ICU, bedside devices send continuous streams of data through the electronic medical record system, through which the clinical team (e.g., nurses, cardiologists, pulmonologists, anesthesiologists, and pharmacologists, etc.) interact with each other and HIT to diagnose the patient's condition.

** Intensivist refers to board-certified physicians who are additionally certified in the subspecialty of critical care medicine, which could also include neurointensivists, anesthesiologiests, as well as those working in pediatrics and surgery. It can also refer to all clinicians, e.g., critical-care nursing staff, whose workspace is concentrated in the intensive care unit or other forms of critical care. In this paper, the author often uses the word "clinician" and "intensivist" interchangeably. However, in using the word "intensivist" he is giving special attention to clinical activity and clinician cognitive workflow in the ICU. 
over a period of two years, with $42 \%$ of incidents related to medication administration and $20 \%$ related to incorrect or incomplete delivery of care (Pronovost, et al., 2006). Researchers argue that communication is frequently interrupted and of poor quality, leading to inefficiencies and potential errors in the ICU (O'Connor et al., 2009). Increased length of stay, increased patient harm, and increased resource utilization have been associated with ineffective communication (Sexton, Thomas, \& Helmreich, 2000).

Team Collaboration: Collaboration is defined as the process of decision-making involving joint activity and ownership of decisions, and collective responsibility for outcomes (McCaffrey et al., 2010). Measures of the quality of patient ICU care can also be assigned to high degrees of collaboration between nurses and doctors, which has a direct impact on improving patient mortality rates and reducing the average length of stay of patients. For this reason, investigations of communication and error in the ICU offer valuable information for understanding the connection between collaborative teamwork, reduction of error, and overall patient safety (Reader, Flin, \& Cuthbertson, 2007). Maxson et al., (2011) state that as the "complexity of patient care increases and more standardization of postoperative pathways occurs, good communication and collaboration between multidisciplinary teams of caregivers will be essential (p. 34)." Critical care requires substantial cognitive work, with a synchronization of people, technology and facilities. Critical care also requires that individual cognitive tasks be distributed (Nemeth, 2008). Good communication and collaboration between multidisciplinary teams is essential, since nurses and physicians have significantly different perceptions of clinical decision-making (Maxson et al., 2011).

Moreover, communication and the distribution of intelligence across clinical team members must be contextually relevant when using HIT. To strengthen the collaborative experience, it is now imperative to recognize that the social experience is transferred not only to others, but also to information technology (Tikhomirov, 1999). Tikhomirov acknowledged that the manifestation of new problems contributed to the human delegation of tasks to computers. As such, he asked: what is the nature of the activity performed by humans in the context of advanced computerization, and how does human activity change when humans use computers? He notes that to "shift responsibility to the computer could promote the formation of superficial and even meaningless goals" (Tikhomirov, 1988, p.189).

\section{Distributed cognition and HIT}

The increasing use of HIT has helped to improve real-time collaboration among clinical teams, while reducing or eliminating decision latency through clinician-

* Intensivists work in highly stressful environments in which they monitor several criticallyill patients simultaneously, usually within a suite of ICU rooms. In such critical care spaces, there are considerable demands on their time and physiological and psychological reserves. The contextual outcome of patient monitoring, with the analysis of both numeric and textual data, and the treating of complex medical problems, is labor intensive and time-consuming, with cognitive loads often exceeding mean expectations for clinical support. Synchronous and asynchronous communication (for the purposes of expediting and increasing the accuracy of decision-making) with fellow intensivists is limited by available technologies. 
centered tools that support more effective communication. The goal is to maximize cognitive capabilities, mitigate constraints associated with collaboration and coordination between team members in the form of communication activities such as dialogue, and to exchange patient diagnostic information. While human intelligence in support of critical care has focused primarily on individual cognition or cognitive load, the work of intensivists is intrinsically collective, with no one person being chiefly able to execute all or most of the clinical activities. As such, complex cognitive processes that underlie critical care medicine need communication systems that can support the mitigation of diagnostic error by not focusing on the thought process of any one individual.

Rather, clinical activity resides not in the mind of any particular individual, but is distributed across the minds of multiple clinicians, technologies, and data sources (Cohen et al., 2006; Nemeth, 2008). Intensivists experience what we refer to as "distributed cognition," being part of a broader clinical team who engage in patient support either face-to-face or through an assortment of HIT (Cohen et al., 2006; Rajkomar, \& Blandford, 2011; Hollan, Hutchins, and Kirsch, 2000, \& Hutchins, 1995). ${ }^{*}$ It is not unusual to find team communication failure cited as a "root cause" of healthcare accidents. Single-factor solutions, such as standards on how to conduct patient record hand-offs, are recommended in reaction to such conclusions. From a social construction perspective, efforts to improve information transmission are inherently limited, because they fail to address how enduring patterns of communication both create and sustain a team's definition of itself and its situation. However, healthcare team communication is both about transmission and a social construction or framework in which team members develop a set of clinical goals, roles, and behavior that help to establish order in a work environment (Pearce, 2006).

What is imperative is the need to examine healthcare team communication along with the evolving complexity of the activity's context, the innovation of new HIT systems, and their impact on the accurate transmission of information that supports collaboration. In looking for ways to reduce the fragmentation of communication systems that avoid the traditional and ineffective hierarchical model of the division of labor, healthcare teams should explore alternative models of team activity that promote "shared situational awareness and support distributed action." (p. 15).

Figure 1 illustrates the complexity of the ICU environment, with clinical workers placed in three zones of activity: in the ICU, in the hospital, and outside the hospital. Through the use of a medical information visualization system, referred to as MIVA (medical information visualization assistant), its mobile technology supports complex data visualization. Specifically, MIVA has been designed to enhance and maximize the clinician's ability to control what data is visualized during a specific context-related patient episode or general periodic diagnosis. Systems

* The theory of distributed cognition was developed by Hutchins (1995), and addresses cognitive processes not confined to the thinking of an individual, but rather distributed among several individuals by means of any variety of external artifacts (i.e., analog or electronic) or internal cognitive functions (i.e., short or long-term memory). Together, the external and internal resources contribute to a greater composited computational system, with a much broader capacity than any individual could be constituted (Cohen et al. 2006). 
like MIVA can offer further support to extend clinical joint activity, giving new meaning to "using vision to think" and the potential to do more than supplement human intelligence (Card, Mackinlay, \& Shneiderman, 1999). MIVA can aid in identifying latent systemic conditions that lead to medical error and facilitate the formation of joint clinical creative intelligence (Cohen et al., 2006). By using the mediating power of visualization, we are bridging visual form, creative extrapolation, and comprehension to produce new clinical knowledge (Kazmierczak, 2003). By exploiting the brain's visual engine, clinicians are empowered to think creatively about complex patient data, while easing cognitive load - hence, amplifying cognition and discovering new diagnostic knowledge.

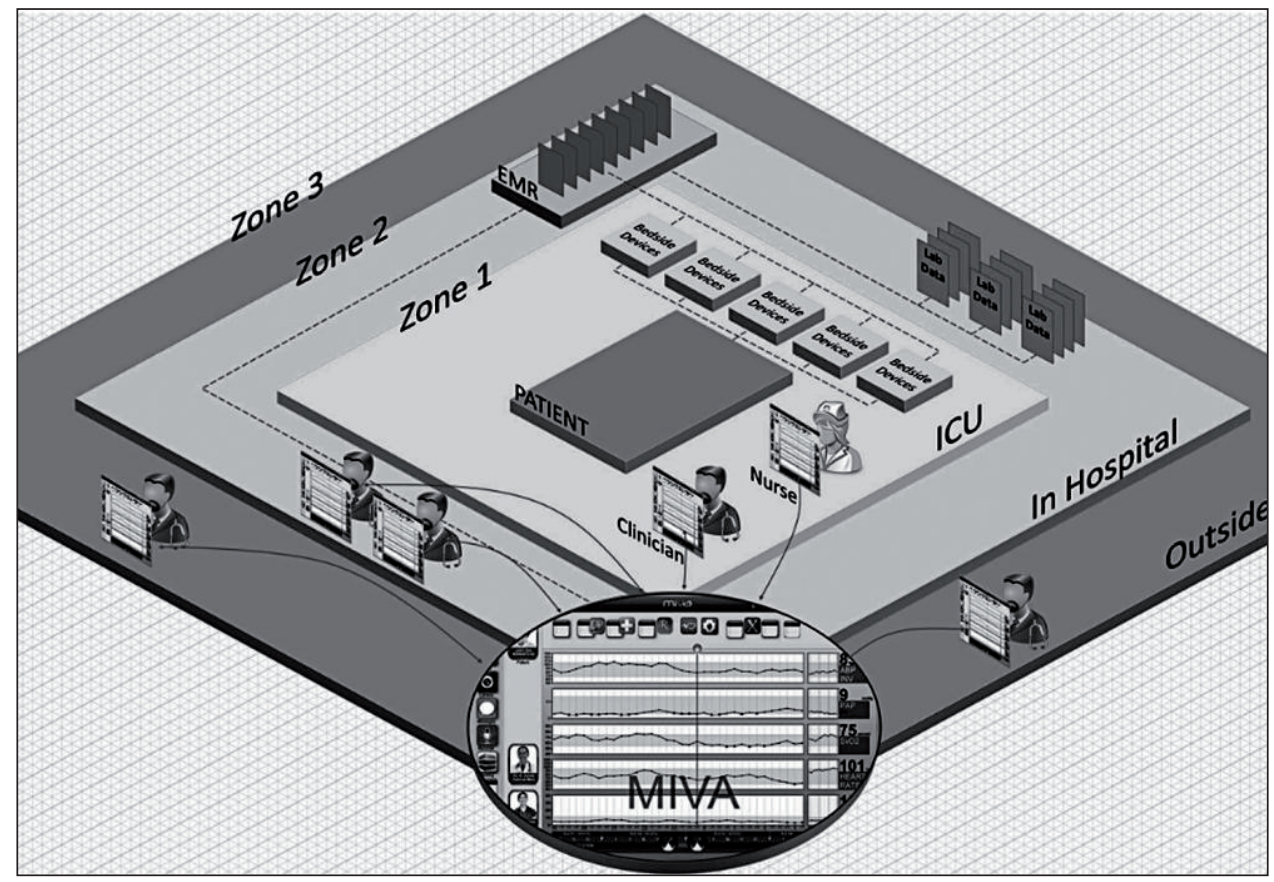

Figure 1. Shows how bio data flows from the patient through the bedside device to the EMR (electronic medical record) to MIVA. Clinicians experience an increase in distributed intelligence during joint activity across all three zones for both communication and patient data, thus facilitating distributed creative activity regardless of geographic location.

Figure 1 demonstrates the general practice of daily activity and how coordination mechanisms and communication flow facilitate a distribution of information that can support critical care patients within the confines of complex ICU settings (Doherty, Karamanis, \& Luz, 2012). It also shows that managing the increased levels of geographic and temporal distribution of activity, and the near-ubiquitous accessibility of patient data via HIT, provides the potential for "workflow-based tools." The use of technologies supporting information exchange has had an immense impact on the way work is carried out and distributed between individuals. This trend towards increased distribution of information and tasks across administrative, spatial and temporal boundaries is referred to by Gerson (2008) as "increased reach." Increased reach raises a number of profound challenges within an 
activity system, where members need to coordinate their goals and tasks with others, communicate, and generally maintain awareness of workflow through an increase of distributed knowledge of the patient's condition and patient data. While HIT has enabled an exponential distribution of knowledge, it has also generated a condition where the devices used for communication and coordination differ from those employed in normal face-to-face situations (Doherty, Karamanis, \& Luz, 2012).

By no longer being bound to the desktop, communication and the distribution of information is pervasively available in every kind of environment. The most distributed collaborative approach is achieved through mobility and its corresponding benefits, such as flexibility, agility, and support for creative activities. The utilization of mobile computing applications (e.g. smartphones and tablets) in the ICU has the potential to support a vast array of functionality and shared creative activity, e.g., data display and analysis, communication, coordination, and consultation (synchronously and asynchronously) with other clinicians, and the final diagnosis. A more significant benefit in using mobile computing, however, is the potential for "real-time activity sharing" among the ICU intensivists team (Bardram, 2005).

HIT tools can cause communication and collaboration to become creative, lead to an increase in cognitive acuity, and generate new psychic formations that can give rise to new motives and renewed objects. As Tikhomirov argues, motives are "not just conditions for developing actual intellectual activity, but also factors influencing its productivity and structure" (Tikhomirov, 1999, p. 350). For this reason, technologies that support clinical activity can assist in stabilizing cognitive need and the formation of new goals in the subject's activity, which Tikhomirov holds as being one of the fundamental acts in the structure of creative activity (1999).

\section{Distributed creative activity}

In a most practical way, Tikhomirov's view of "joint practical activity" is grounded in Vygotsky's universal law of development, which posits that the function of the human mind first emerges as socially distributed, i.e., that cognition is both distributed and embodied systemically (Tikhomirov, 1999). For example, in healthcare, joint activity is mediated by distributed cognition in predicting clinical events, planning courses of action, and diagnosing conditions (Cohen et al., 2006; Cook, Woods, \& Miller, 1998; Hutchins, 1995; Nemeth, 2008). In brief, these clinical activities enable a shift from individual intelligence to a distribution of creative activity across both minds and technologies, and provide insight into how clinical intelligence is shared and transformed from a sociocultural perspective. Clinical activity includes the distribution of clinical knowledge as part of cultural-historical development. Hence, the social distribution of cognition (in the context of the ICU) results in a unique development of the intensivist mind, and of the relationship between people and artifacts, which has a direct impact on diagnostic outcomes and the transformation of the sociocultural role of every clinician.

What arises from this process is distributed creative activity (DCA): the intercognitive distribution of creative intelligence among clinicians and HIT (subjects and technologies). The theory holds that the creative augmentation of clinical cog- 
nition plays a central role in diagnostic healthcare, where intelligence is distributed across a creative activity system - between clinicians, patient, and technologies. As such, creative intelligence is jointly embodied and activity is systemic, where cognition is not mere information or computational processing, but a distribution of intelligence and a sharing of sociocultural development.

In application, the clinician and HIT participate qualitatively in an intelligence ecosystem, where computers mediate the distribution of cognition, sharing those functions that the mind is unable to perform due to limits in its computational complexity and speed. As such, the distribution and analysis of patient data becomes a shared repository from which clinicians can combine their diagnostic skills and resident knowledge with HIT to arrive at diagnostic conclusions more accurately and efficiently.

In DCA, shared knowledge is not only part of an activity system, but also a distribution of cognition in the social world of clinical care. Cultural mediation here implies more than the distribution of cognition or the mediation of activity through artifacts, humans, and context, but a greater augmentation of cognition and distribution of higher thinking due to a distributed work that includes the use of information technology (Salomon, 1993, p. 13). For example, the MIVA system constructs visual signs that have powerful mediating effects on cognition (Rind et al., 2013; Spence, 2002). Human information processing is often limited and constrained by speed, memory, and a range of personal cognitive disabilities. To address these limits and irregularities, MIVA can be used to amplify cognition in ways that support the brain's ability to make complex associations and extrapolations, thus identifying extended knowledge, meaning, and visual intelligence (Cowan, 2000; Vygotsky, 1978/1934; Wise, 1999).

\section{Future work}

Ongoing studies on critical care activity continue to provide significant evidence to suggest that distributed cognitive activity underlying clinical performance should not focus on individuals, but on complex social systems that constitute joint clinical activity. Previous research has found support for the claim that the majority of intensivists engaging in collaborative activity in the ICU, using communication IT such as wireless e-mail, improve team relationships, as well as staff satisfaction and patient care (O'Connor et al., 2009). This has been found to improve communication speed by $92 \%$, communication reliability by $92 \%$, coordination by $88 \%$, reduce staff frustration by $75 \%$, and result in faster (90\%) and safer (75\%) patient care. We believe that clear, rapid, appropriate, and accurate communication is essential to delivering safe patient care, from which real joint activity among intensivists is vital for patient care and job satisfaction (O'Connor et al., 2009).

The theoretical model of DCA proposed in this paper is grounded in traditional activity theory, with an extended theoretical component that is applied to HIT (as illustrated in Figure 1). As such, future work includes the evaluation of this model through observation of DCA in the ICU. This specific study will iden-

* Studies show that humans do not have sufficient means of storing information; we only poses "small amounts of rapid-access storage," short-term memory (Simon, 1998, p. 61). 
tify and compare intensivist cognitive load, workflow, and clinical decision support (CDS) system use. Our objective is to: 1) identify the root causes and underlying mechanisms of ICU error related to the effects of diagnostic tools/systems on clinical work and cognitive load; with the long term goal of designing transformative CDSs that increase protection of patients from adverse events and provide greater safety, while reducing intensivists' time, effort, work, and cognitive resources. The rationale for our work is to provide a more complete and advanced understanding of the individual, interrelated, and interactive factors of CDS, cognitive workflow, and inter-team clinical communication that contributes to medical error in the ICU. Our project will inform the further design and development of an ICU clinical visualization, communication and decision support tool that provides ICU staff with capabilities of greater control over data and intra-communication at the point of care.

\section{Conclusion}

Healthcare is one of the most preeminent environments to observe creative activity in real time, as the mind's social and historical development transform before us. For this reason, the purpose of observing clinical work from a distributed cognition perspective is to understand joint activity and the flow of knowledge between each collaborative agent, whether technological or human. Tikhomirov's quest to better understand "how computers affect the development of intellectual activity" is explicitly revealed in the clinical environment. In particular, his efforts to understand the positive effects of computers on the development of creative activity provide valuable instruction to activity theorists, especially with respect to their influence on new goal formation (Tikhomirov, 1972, pp. 186-87) as it might apply in critical care environments. As he notes, "new needs and new motives are important sources of creative activity" because it is a "unit of life that includes the generation of new psychic formations, the real function of which is giving humans the opportunity to generate a new world of objects" (Tikhomirov, 1988, Tikhomirov, 1999, pp. 349-351). However, through HIT (in particular MIVA), complex clinical activity becomes a super-augmentation of interpersonal cognition in ways that underpin creative diagnosis in healthcare. For these reasons, distributed creative activity brings an extended meaning to creative activity and an advanced notion about the social distribution of cognition in sociocultural development with respect to the context of public health and the care of the critically ill.

\section{Acknowledgements}

Special thanks to my graduate student research team (Yamini Karanam (Ph.D. Cand.), David Chartash (Ph.D. Cand.), Michael Zhang (M.S. Student), and Elliot Li (M.S. Student)) for their work with me in developing the working model of clinical activity as illustrated by Figure 1, including the work of creating the graphic. Also, many thanks to my graduate student, Preethi Srinivas (Ph.D. Cand.) for her editorial comments. All graduate students are supported through a Solution Center Grant and the Indiana University School of Informatics and Computing, IUPUI, Indianapolis, IN USA. 


\section{References}

Alameddine, M., Dainty, K. N., Deber, R., \& Sibbald, W. J. (2009). The intensive care unit work environment: Current challenges and recommendations for the future. Journal of Critical Care, 24, 243-248. doi: 10.1016/j.jcrc.2008.03.038

Aleksandrova-Howell, M. Abramson, C. I., and Craig, D. P. (2011). Coverage of Russian psychological contributions in American psychology, International Journal of Psychology, 47(1), $76-87$.

Arford, P. (2005). Nurse-physician communication: An organizational accountability. Nursing Economics, 23(2), 72-77.

Babaeva, Y. D., Berezanskaya, N. B., Vasilyev, I. A., Voiskounsky, A. E., Kornilova, T. V. (2009). On the contribution of $\mathrm{O}$. K. Tikhomirov in methodology, theory, and experimental and practice of psychological science. Methodology and History of Psychology, 4(4), 9-27.

Bade, R., Miksch S., \& Schlechtweg, S. (2004). Connecting time-oriented data and information to a coherent interactive visualization. In CHI '04, ACM Conference on Human Factors in Computing Systems, 6(1), 105-112.

Bardram, J. E. (2005). Activity-based computing: support for mobility and collaboration in ubiquitous computing. Personal and Ubiquitous Computing, 9, 312-322. doi: 10.1007/s00779004-0335-2

Beuscart-Zéphir, M. C., Pelayo, S., Anceaux, F., Maxwell, D., \& Guerlinger, S. (2007). Cognitive analysis of physicians and nurses cooperation in the medication ordering and administration process. International Journal of Medical Informatics, 76, 65-77. doi: 10.1016/j. ijmedinf.2006.05.022

Block, S. D. (2001). Helping the clinician cope with death in the ICU. In: Curtis, J. F., Rubenfeld, G. D., (Eds)., Managing death in the ICU. The transition from cure to comfort. (pp. 165-182). New York: Oxford University Press.

Boyle, D., \& Kochinda, C. (2004). Enhancing collaborative communication of nurse and physician leadership in two ICUs. Journal of Nursing Administration, 34(2), 60-70. doi: 10.1097/00005110-200402000-00003

Brushlinky, A. V. (1990). The activity of the subject and psychic activity. In V. A. Lektorsky (Ed.). Activity: Theories, methodology and problems. Orlando: Paul M. Deutsch Press.

Card, S. Mackinlay, J. Shneiderman, B. (1999). Readings in information visualization: Using vision to think. New York: Morgan Kaufmann Publishers.

Cohen, T., Blatter, B., Almeida, C., Shortliffe, E., \& Patel, V. (2006). A cognitive blueprint of collaboration in context: distributed cognition in the psychiatric emergency department. Artificial intelligence in Medicine, 37(2), 73-83. doi: 10.1016/j.artmed.2006.03.009

Collins, S. A. \& Currie, L. M. (2009). Interdisciplinary Communication in the ICU. Studies in Health Technology and Informatics, 146, 362-366.

Cook, R., Woods, D. \& Miller, C. (1998). A Tale of Two Stories: Contrasting Views of Patient Safety. Chicago: National Health Care Safety Council of the National Patient Safety Foundation, American Medical Association.

Cowan N. (2000). The magical number four in short-term memory: A reconsideration of mental storage capacity. Journal of Behavioral Brain Science, 24, 87-185. doi: 10.1017/ S0140525X01003922

Doherty, G., Karamanis, N. \& Luz, S. (2012). Collaboration in translation: The impact of increased reach on cross-organizational work. Computer Supported Cooperative Work, 21, 525-535. doi: 10.1007/s10606-012-9175-1

Donchin, Y., Gopher, D., Olin, M., Badihi, Y., Biesky, M., Sprung, C. L., Pizov, R., \& Cotev, S. (1995). A look into the nature and causes of human errors in the intensive care unit. Critical Care Medicine, 23(2), 294-300. doi: 10.1097/00003246-199502000-00015 
Dykstra R. (2002). Computerized physician order entry and communication: reciprocal impacts. Proceedings of the AMIA Symposium, pp. 230-234.

Eisenberg, E. M. (2008). The Social Construction of Healthcare Teams (Chap. 2). In C. P. Nemeth (Ed.), Improving healthcare team communication: Building on lessons from aviation and aerospace (9-20). Aldershot, UK and Burlington, USA: Ashgate Publishing Ltd.

Eisenberg, E., Goodall Jr., H.L. Tretheway, A. (2007). Organizational communication: Balancing creativity and constraint, 5th ed. New York: St. Martin's Press.

Engeström, Y., Miettinen, R. Punamaki, R. L. (Eds.) (1999). Perspectives on activity theory. Cambridge, UK: Cambridge University Press.

Faiola, A., Boston-Clay, C., Jones, J., Newlon, C., \& Downey, M. (2012). Managing Patient Health Across Diverse Spaces: Using Activity Theory to Model Clinical Decision Support for the Home. In CHI '12 Extended Abstracts on Bridging Clinical and Non-clinical Health Practices: Opportunities and Challenges (Workshop) (Austin, TX, May 5, 2012). ACM Press, New York, NY.

Fletcher, K. E., Underwood, W., Davis, S. Q., Mangrulkar, R.S., McMahon, L. F., \& Saint, S. (2005). Effects of work hour reduction on residents' lives: A systematic review. Journal of the American Medical Association, 294: 1088-100. doi: 10.1001/jama.294.9.1088

Gerson, E. M. (2008). Reach, Bracket, and the Limits of Rationalized Coordination: Some Challenges for CSCW. In: M. S. Ackerman, C. A. Halverson, T. Erickson, and W. A. Kellogg (eds.): Resources, Co-Evolution and Artifacts. London: Springer, pp. 193-220. doi: 10.1007/9781-84628-901-9_8

Hollan, J., Edwin Hutchins, \& Kirsch, D. (2000). Distributed Cognition: Toward A New Foundation for Human-Computer Interaction Research. ACM Transactions on Computer-Human Interaction (TOCHI), 7(2), 174-196. doi: 10.1145/353485.353487

Horn, W., Popow, C. \& Unterasinger, L. (2001). Support for fast comprehension of ICU data: Visualization using metaphor graphics. Methods of Information in Medicine, 40, 421-424.

Hutchins, E. (1995). Cognition in the Wild. Cambridge, MA: MIT Press.

Institute of Medicine (2000). Committee on Quality of Health Care in America. In: Kohn LT, Corrigan JM, Donaldson MS, editors. To Err is Human Building a Safer Health System. Washington, DC: National Academy Press.

Kazmierczak, E. T. (2003). Design as meaning making: From making things to the design of thinking. Design Issues, 19(2), 45-59. doi: 10.1162/074793603765201406

Khairat S, \& Gong Y. (2011). Enhancing Patient Safety Through Clinical Communication Knowledge Representation. e-Health Networking Applications and Services Healthcom, $201113^{\text {th }}$ IEEE International Conference on 2011:130-3.

Kozhanova, I. (2003). Tsennostno-motivatsionniye harakteristiki spetsialistov kak factor vybora sposobov vzaimodeystviya s informatsionnymi tehnologiyami [High-motivational characteristics as a factor selection methods of interaction with information technology] (Unpublished doctoral dissertation). Moscow.

Leontev, A. N. (1981). Problems of the Development of the Mind. Moscow: Progress.

Lindfors, P. M., Nurmi, K. E., Meretoja, O. A., Luukkonen, R. A., Viljanen, A. M. Leino, T. J., \& Härmä, M.I. (2006). On-call stress among Finnish anaesthetists. Anaesthesia, 61, 856-66. doi: 10.1111/j.1365-2044.2006.04749.x

Maxson, P. M., Dozois, E. J., Holubar, S. D., Wrobleski, D. M., Overman-Dube, J. A., Klipfel, J. M. \& Arnold, J. J. (2011). Enhancing Nurse and Physician Collaboration in Clinical Decision Making Through High-fidelity Interdisciplinary Simulation Training. Mayo Clinic Proceedings, 86(1), 31-36. doi: 10.4065/mcp.2010.0282

McCaffrey, R. G., Hayes, R., Stuart, W., Cassell, A., Farrell, C., Miller-Reyes, C., \& Donaldson, A. (2010). A Program to Improve Communication and Collaboration Between Nurses and 
Medical Residents. Journal of Continuing Education in Nursing, 41(4), 172-178. doi: 10.3928/00220124-20100326-04

Nemeth, C. P. (2008). The context for improving healthcare team communication, In C. P. Nemeth (Ed.), Improving Healthcare Team Communication: Building on Lessons from Aviation and Aerospace, Burlington: Ashgate Publishing Ltd.

O'Connor, C., Friedrich, J. O., Scales, D. C. \& Adhikari, N. K. (2009). The use of wireless e-mail to improve healthcare team communication. Journal of the American Medical Informatics Association, 16(5), 705-713. doi: 10.1197/jamia.M2299

Patel, V. L., Zhang, J., Yoskowitz, N. A., Green, R. \& Sayan, O. R. (2008). Translational cognition for decision support in critical care environments: A review. Journal of Biomedical Informatics, 41(3), 413-431. doi: 10.1016/j.jbi.2008.01.013

Pearce, B. (2006). Toward Communicative Virtuosity, presented at the seminar 'Modernity as a Communication Process (Is Modernity “On Time?”)' (Moscow, Russia, April 15).

Pohl, M., Wiltner, S., Rind, A., Aigner, W., Miksch, S., Turic, T., \& Drexler, F. (2011). Patient development at a glance: An evaluation of a medical data visualization. In P. Campos, N. Graham, J. Jorge, N. Nunes, P. Palanque, and M. Winckler (Eds.). Proc. IFIP Human-Computer Interaction - INTERACT 2011, Part IV, 292-299. Heidelberg: Springer. doi: 10.1007/9783-642-23768-3_24

Pronovost, P., Thompson, D., Holzmueller, C. G., Lubomski, L. H., Dorman, T., Dickman, F., Fahey, M., Steinwachs, D. M., Engineer, L., Sexton, J. B., Wu, A. W., \& Morlock, L. L. (2006). Toward learning from patient safety reporting systems. Journal of Critical Care, 21, 305-315. doi: 10.1016/j.jcrc.2006.07.001

Rajkomar, A. \& Blandford, A. (2011). Distributed cognition for evaluating healthcare technology. Proceedings of the 25th 2011 BCS Conference on Human-Computer Interaction, 341-350.

Reader, T. W., Flin, R., \& Cuthbertson, B. H. (2007). Communication skills and error in the intensive care unit, Current Opinion in Critical Care, 13(6), 732-736. doi: 10.1097/ MCC.0b013e3282f1bb0e

Rind, A, Wang, Taowei, D, Aigner, W, Miksch, S. Wongsuphasawat, K., Plaisant, C., Shneiderman, B. (2013). Interactive information visualization to explore and query electronic health records. Foundations and Trends in Human-Computer Interaction, 5(3), 207-298. doi: $10.1561 / 1100000039$

Rozin, V. M. (2002). The Value Foundations of the Conceptions of Activity in Psychology and Contemporary Methodology. Russian Studies in Philosophy, 40(2), 76-90. doi: 10.2753/ RSP1061-1967400276

Salomon, G. (Ed.). (1993). Distributed Cognitions: Psychological and Educational Considerations. Cambridge, UK: Cambridge University Press.

Senge, P. (1990). The Fifth Discipline. New York: Free Press.

Sexton, J. B., Thomas, E. J., and Helmreich, R. L. (2000). Error, stress, and teamwork in medicine and aviation: Cross sectional surveys. British Medical Journal, 320, 745-749. doi: 10.1136/ bmj.320.7237.745

Shu, K., Boyle, D., Spurr, C., Horsky, J., Heiman, H., O’Connor, P., Lepore, J., \& Bates, D. W. (2001). Comparison of time spent writing orders on paper with computerized physician order entry, Studies in Health Technology Information, 84, 1207-1211.

Simon, H. A. (1998). The sciences of the artificial, 3rd ed. Cambridge, MA: MIT Press.

Spence, R. (2002). Sensitive encoding to support information space navigation: a design guideline. Information Visualization, 1, 120-129. doi: 10.1057/palgrave.ivs.9500019

Tikhomirov, O. K. (1972). The psychological consequences of computerization. In O. Tikhomirov (Ed.). Man and Computer. Moscow University Press.

Tikhomirov, O. K. (1988). Psychology of Thinking. Moscow: Progress Publishers. 
Tikhomirov, O. K. (1999). The theory of activity changed by information technology. In: Perspectives on Activity Theory, Y. Engeström, R. Miettinen, and R. L. Punamaki (Eds.). Cambridge, MA: Cambridge University Press. doi: 10.1017/CBO9780511812774.023

Tufte, E. R. (1997). Visual explanations: Images and quantities, evidence and narrative. Cheshire, CT: Graphic Press.

Voiskunsky, A. E., Zhdan, A. N., \& Tikhomirov, O. K. (Eds.). (1999). Traditsii I perspektivy deyatelnostnogo podhoda $\mathrm{v}$ psihologii: shkola Leontyeva [Traditions and perspectives of the activity approach in psychology: Leontiev School]. Moscow: Smysl.

Vygotsky, L. S. (1978/1934). Mind in Society: The Development of Higher Psychological Processes. Cambridge, MA: Harvard Press.

Winters, B., Custer, J., Galvagno, M., Colantuoni, E., Kapoor, S., Lee, H., Goode, V., Robinson, K., Nakhasi, S., Pronovost, P., \& Newman-Toker, D. (2012). Diagnostic errors in the intensive care unit: a systematic review of autopsy studies. BMJ Quality \& Safety, 21(11), 894-902. doi: 10.1136/bmjqs-2012-000803

Wise, J. A., Thomas, J. J., Pennock, K., Lantrip, D., Pottier, M., Schur, A., \& Crow, V. (1999). Visualizing the non-visual: spatial analysis and interaction with information for text documents. In Card S. K., Mackinlay, J. D. (Eds.). Readings in Information Visualization: Using Vision to Think (pp. 442-450). San Francisco: Morgan Kaufmann Publishers Inc.

Received: 08 September 2013

Accepted: 10 November 2013

Available online: 15 December 2013 